\title{
Amygdala Regulation of Immediate-Early Gene Expression in the Hippocampus Induced by Contextual Fear Conditioning
}

\author{
Nicole C. Huff, Matthew Frank, Karli Wright-Hardesty, David Sprunger, Patricia Matus-Amat, Emily Higgins, and \\ Jerry W. Rudy \\ Department of Psychology, Center for Neuroscience, University of Colorado, Boulder, Colorado 80309
}

The basolateral nuclei of the amygdala (BLA) are thought to modulate memory storage in other brain regions (McGaugh, 2004). We reported that BLA modulates the memory for both an explored context and for contextual fear conditioning. Both of these memories depend on the hippocampus. Here, we examined the hypothesis that the BLA exerts its modulatory effect by regulating the expression of immediate-early genes (IEGs) in the hippocampus. The main findings of these experiments were: (1) Arc activity-regulated cytoskeletal protein $(A r c)$, an immediate-early gene (also termed Arg 3.1) and c-fos mRNA are induced in the hippocampus after a context exposure, or context plus shock experience, but not after an immediate shock; and (2) BLA inactivation with muscimol attenuated the increase in Arc and c-fos mRNA in the hippocampus associated with contextual fear conditioning but did not influence Arc mRNA associated with context exploration. These results support the hypothesis that the amygdala modulates contextual fear memory by regulating expression of IEGs in the hippocampus.

Key words: contextual fear; amygdala; modulation; consolidation; immediate-early genes; Arc; c-fos

\section{Introduction}

The concept of memory modulation is central to understanding some of the dynamics involved in establishing an enduring memory trace (Packard et al., 1995; McGaugh, 2002). The modulation framework assumes that experience has two effects: (1) it activates neural processes that represent and can store the experience, and (2) it engages other neural and hormonal systems that can alter the storage process. Over the past 30 years, this framework has generated an enormous amount of information about the hormonal factors and neural systems that are central to memory modulation (McGaugh et al., 1999; McGaugh, 2002). From this work, the basolateral amygdala (BLA) has emerged as the principal region that orchestrates the storage of memories in many other regions (McIntyre et al., 2003; McGaugh, 2004).

A great deal is known about neurotransmitter and hormonal influences on the amygdala that contribute to its modulating influence on other brain regions (Gold and van Burskirk, 1976; McGaugh et al., 1999; Roozendaal, 2003). Ultimately, however, memory strength is thought to depend on the cellular processes that produce changes in the synapses that represent the learning experience. Thus, it is possible that the amygdala may modulate experience-dependent gene products at synapses that support the memory. McIntyre et al. (2005) recently provided strong support for this hypothesis. They reported that the amygdala modulates both

Received July 28, 2005; revised Dec. 20, 2005; accepted Dec. 21, 2005

This work was supported by National Institutes of Health Grant R01 MH61316-05 (J.W.R.). We thank Christa McIntyre, James McGaugh, and John Guzowski for their comments on this manuscript.

Correspondence should be addressed to Jerry W. Rudy, Department of Psychology, University of Colorado, 345 UCB, Boulder, C0 80309. E-mail: JRudy@clipr.colorado.edu.

DOI:10.1523/JNEUROSCI.4964-05.2006

Copyright $\odot 2006$ Society for Neuroscience $\quad 0270-6474 / 06 / 261616-08 \$ 15.00 / 0$ inhibitory avoidance learning and the expression of Arc protein, an immediate-early gene (IEG) product, in the hippocampus.

We reported that inactivation of the amygdala with muscimol, a $\mathrm{GABA}_{\mathrm{A}}$ receptor agonist, impairs the consolidation of both contextual fear conditioning and memory for context (Huff and Rudy, 2004; Huff et al., 2005), both of which depend on the hippocampus (Barrientos et al., 2002; Rudy et al., 2002; MatusAmat et al., 2004). It is possible that the modulating influence of the amygdala on context memories may also be accompanied by an influence on the mRNA regulation of IEGs such as Arc and c-fos.

Arc, also termed Arg 3.1 (Link et al., 1995), and c-fos mRNA are rapidly induced in response to synaptic activity. Arc is especially interesting, because it is targeted to specific regions of dendrites that receive synaptic stimulation (Steward et al., 1998). Moreover, infusions of Arc antisense oligodeoxynucleotides into hippocampus can impair the maintenance of long-term potentiation and memory for place learning (Guzowski et al., 2001), as well as inhibitory avoidance learning (McIntyre et al., 2005). A variety of learning experiences are known to induce c-fos (Hughes and Dragunow, 1995; Herrera and Robertson, 1996; Campeau et al., 1997; Tischmeyer and Grimm, 1999; MontagSallaz and Buonviso, 2002). Moreover, intrahippocampal blockade of c-fos protein product with antisense oligodeoxynucleotides impairs memory for brightness discrimination learning (Grimm et al., 1997) and spatial water-maze training in rats (Guzowski, 2002).

Given our rationale, the present experiments focused on the following: (1) the expression of IEG mRNA in the hippocampus induced by contextual fear conditioning and its subcomponents, context exploration, and shock only; and (2) the regulation of this expression by the BLA. 


\section{Materials and Methods}

Subjects

Adult male Sprague Dawley rats weighing 250-275 g at the time of surgery were housed two in each cage at $25^{\circ} \mathrm{C}$ on a $12 \mathrm{~h} \mathrm{light/dark} \mathrm{cycle}$ (lights on at 7:00 A.M.). Rats were allowed ad libitum access to food and water. Contextual fear conditioning, context exposure, or immediate shock occurred between 8:00 and 11:30 A.M. in all experiments. The experiments were conducted in accordance with protocols approved by the University of Colorado Animal Care and Use Committee.

\section{Surgery}

In experiments 3 and 4, rats under halothane anesthesia were placed in stereotaxic apparatus (Kopf Instruments, Tujunga, CA) and implanted bilaterally with chronic stainless-steel guide cannulas (Plastics One, Roanoke, VA). The following coordinates, from Paxinos and Watson (1998), were used for bilateral guide cannula implantation aimed at the BLA region: from bregma, anteroposterior $-3.0 \mathrm{~mm}$, mediolateral \pm 4.8 $\mathrm{mm}$, dorsoventral $-7.5 \mathrm{~mm}$, with internal injection cannula $-8.5 \mathrm{~mm}$. Guide cannulas were secured with dental acrylic and three small screws and, to maintain patency, fitted with obturators that extended $1 \mathrm{~mm}$ beyond the tip of the guide cannula. Rats were allowed to recover for $7 \mathrm{~d}$.

\section{Apparatus}

The conditioning chamber consisted of an Igloo ice chest $(54 \mathrm{~cm}$ long $\times$ $30 \mathrm{~cm}$ wide $\times 27 \mathrm{~cm}$ high) with a white interior. A speaker and an activated 6-W clear light bulb were mounted on the ceiling of each chest. The ice chest door was open the entire time, and the room was illuminated by two $60 \mathrm{~W}$ light bulbs. The conditioning chambers $(26 \mathrm{~cm}$ long $\times$ $21 \mathrm{~cm}$ wide $\times 24 \mathrm{~cm}$ high) placed inside the chest were made of clear plastic and had window screen tops. The shock was delivered through a removable floor of stainless-steel rods (model E63-23-MOD001; Coulbourn Instruments, Allentown, PA), each of which was $0.5 \mathrm{~cm}$ in diameter and spaced $1.75 \mathrm{~cm}$, center to center. Each rod was wired to a shock generator and scrambler (model H13-16; Coulbourn Instruments). The chamber was cleaned with water before each rat was pre-exposed or conditioned.

\section{Behavioral procedures}

Handling. The rats were not habituated in any explicit way before the actual experiments. They were of course handled on days in which their cages were changed.

Contextual fear conditioning. Rats were taken two at a time in a black bucket to the conditioning chambers. Rats were in the conditioning context for $5 \mathrm{~min}$, at the end of which a $2 \mathrm{~s}, 1.5 \mathrm{~mA}$ shock was presented. After the shock, rats were immediately removed and returned to their home cage via a black bucket. Rats in the immediate condition were killed immediately after removal from the conditioning chamber. In other cases, rats were returned to their home cage two at a time in a black bucket and then removed 15, 30, or $60 \mathrm{~min}$ after conditioning to be killed.

Context exposure. Rats were transported two at a time from the home cage to the conditioning context in a black bucket with a tight lid. They were then placed in the context and allowed to freely explore for $5 \mathrm{~min}$. The same two rats were then transported back to their home cage in a black bucket. Rats were transported from the home cage in a black bucket two at a time 30 or $60 \mathrm{~min}$ after context exposure to be killed.

Immediate shock. Rats were carried one at a time from their home cage to the conditioning chamber. Immediately after they were placed in the chamber, a $2 \mathrm{~s}, 1.5 \mathrm{~mA}$ shock was delivered. Rats were quickly removed and returned to their home cage. Rats were transported in the black bucket $5,15,30$, or 60 min after the shock to be killed.

\section{Microinjections}

Microinjections were performed before contextual fear conditioning in experiments 3 and 4 . Rats were gently wrapped in a soft towel, and a 33 gauge microinjector (Plastics One) attached to PE50 tubing was inserted through the indwelling guide cannula. The distal end of the PE50 tubing was attached to a $100 \mu$ l Hamilton syringe that was attached to a Kopf microinjection unit (model 5000) that dispensed the desired volume. Bilateral intra-amygdala infusions were in a volume of $0.5 \mu \mathrm{l}$ per side. In experiments 3 and 4, rats were infused with muscimol or vehicle $60 \mathrm{~min}$ before conditioning.

\section{Drugs}

Muscimol (Sigma, St. Louis, MO) was dissolved in Ringer's irrigation (United States Pharmacopeia; Baxter, Deerfield, IL) for a final concentration of $1.0 \mu \mathrm{g} / \mu \mathrm{l}$. Muscimol or vehicle (Ringer's solution) was injected bilaterally $(0.5 \mu \mathrm{l} /$ side $)$ into the BLA region over $2 \mathrm{~min}$.

\section{Real-time quantitative PCR}

Brain extractions. Rats were quickly anesthetized with halothane before decapitation. The whole brain was removed, and the hippocampus was extracted. Tissue was placed in nuclease-free tubes and flash frozen in liquid nitrogen. Tissue was stored at $-80^{\circ} \mathrm{C}$ until processed for reverse transcriptase (RT)-PCR. Arc and c-fos mRNA analysis was performed on tissue from the same subjects within each set of experiments. It should be noted that because of technical problems, we did not obtain data for both $A r c$ and c-fos at all time points.

RNA isolation and enrichment. Total RNA was isolated from tissue based on the method used by Chomczynski and Sacchi (1987). Briefly, tissue was rapidly homogenized in $1 \mathrm{ml}$ of TRIzol reagent (Invitrogen, Carlsbad, CA). After incubation at room temperature for $5 \mathrm{~min}$, homogenate was centrifuged $(12,000 \times g)$ for $15 \mathrm{~min}$ at $4^{\circ} \mathrm{C}$ to remove excess lipids. Chloroform $(200 \mu \mathrm{l})$ was added to supernatant, vortexed, and centrifuged $(12,000 \times g)$ for $15 \mathrm{~min}$ at $4^{\circ} \mathrm{C}$ to achieve phase separation of nucleic acid. Isopropyl alcohol $(500 \mu \mathrm{l})$ was added to aqueous phase to precipitate nucleic acid. Samples were vortexed (1 min) and incubated at room temperature for $10 \mathrm{~min}$ followed by centrifugation $(12,000 \times \mathrm{g})$ for $10 \mathrm{~min}$ at $4^{\circ} \mathrm{C}$. Nucleic acid precipitate was washed twice in $75 \%$ ethanol $(1 \mathrm{ml})$ and centrifuged $(7500 \times g)$ for $5 \mathrm{~min}$ at $4^{\circ} \mathrm{C}$. UV spectrophotometric analysis of nucleic acid was performed at $260 \mathrm{~nm}$ to determine concentration. The 260:280 absorbency ratio was used to assess nucleic acid purity. Samples were DNase-treated (DNA-free kit; Ambion, Austin, TX) to remove contaminating DNA from total nucleic acid and requantitated before $\mathrm{cDNA}$ synthesis.

cDNA synthesis. Total RNA was reverse transcribed into cDNA using the SuperScript II First Strand Synthesis System for RT-PCR (Invitrogen). RNA $(2 \mu \mathrm{g})$ was incubated for $5 \mathrm{~min}$ at $65^{\circ} \mathrm{C}$ in a total reaction volume of $12 \mu \mathrm{l}$ containing random hexamer primers $(5 \mathrm{ng} / \mu \mathrm{l})$ and dNTPs ( $1 \mathrm{~mm}$ ). Samples were chilled on ice for at least $1 \mathrm{~min}$. A cDNA synthesis buffer $(7 \mu \mathrm{l})$, as described by the manufacturer, was added to the reaction and incubated at $25^{\circ} \mathrm{C}$ for $2 \mathrm{~min}$. Reverse transcriptase $(1 \mu \mathrm{l}$; $200 \mathrm{U}$ of SuperScript II) was added to the reaction and incubated at $25^{\circ} \mathrm{C}$ for $10 \mathrm{~min}$ followed by $42^{\circ} \mathrm{C}$ for $50 \mathrm{~min}$. Reaction was terminated by heating to $70^{\circ} \mathrm{C}$ for $15 \mathrm{~min}$. cDNA was diluted twofold in nuclease-free water and stored at $-20^{\circ} \mathrm{C}$.

Primer specifications. cDNA sequences for Arc (GenBank accession number U19866), c-fos (GenBank accession number X06769), rat glyceraldehyde-3-phosphate dehydrogenase (GAPDH; GenBank accession number M17701), and 18s ribosomal RNA (GenBank accession number K01593) were obtained from GenBank at the National Center for Biotechnology Information (NCBI; www.ncbi.nlm.nih.gov). Primer sequences for Arc (forward, 5'-ACAGAGGATGAGACTGAGGCAC-3'; reverse, $5^{\prime}$-TATTCAGGCTGGGTCCTGTCAC-3'; 77 bp product), c-fos (forward, 5'-CTTCCTTTGTCTTCACCTACC-3'; reverse, 5'-CCTTCTCTGACTGCTCACA-3'; 110 bp product), GAPDH (forward, 5' GTTTGTGATGGGTGTGAACC-3'; reverse, 5'-TCTTCTGAGTGGCAGTGATG-3'; 162 bp product), and 18 s ribosomal RNA (forward, 5'-ATGGTAGTCGCCGTGCCTA-3'; reverse, 5' -CTGCTGCCTTCCTTGGATG-3' 126 bp product) were designed using the Qiagen (Hilden, Germany) Oligo Analysis and Plotting Tool (http://oligos.qiagen.com/ oligos/toolkit.php) and tested for sequence specificity using the Basic Local Alignment Search Tool (Altschul et al., 1997) at NCBI. Primers were obtained from Proligo (Boulder, CO). Primer specificity was verified by melt curve analysis (see below, Quantitative real-time PCR).

Quantitative real-time PCR. PCR amplification of CDNA was performed using the Quantitect SYBR Green PCR kit (Qiagen, Valencia, CA). cDNA $(1 \mu \mathrm{l})$ was added to a reaction master mix $(25 \mu \mathrm{l})$ containing $2.5 \mathrm{~mm} \mathrm{MgCl}_{2}$, HotStar TaqDNA polymerase, SYBR Green I, dNTPs, 
fluorescein (10 nM), and gene-specific primers (500 nm each of forward and reverse primer). For each experimental sample, triplicate reactions were conducted in 96-well plates (Bio-Rad, Hercules, CA). PCR cycling conditions consisted of a hot-start activation of HotStar TaqDNA polymerase $\left(94^{\circ} \mathrm{C} ; 15 \mathrm{~min}\right)$ and 40 cycles of denaturation $\left(95^{\circ} \mathrm{C} ; 15 \mathrm{~s}\right)$, annealing $\left(55-58^{\circ} \mathrm{C} ; 30 \mathrm{~s}\right)$, and extension $\left(72^{\circ} \mathrm{C} ; 30 \mathrm{~s}\right)$. A melt curve analysis was conducted to assess uniformity of product formation, primer dimer formation, and amplification of nonspecific products. PCR product was denatured $\left(95^{\circ} \mathrm{C} ; 1 \mathrm{~min}\right)$ and annealed $\left(55^{\circ} \mathrm{C} ; 1 \mathrm{~min}\right)$ before melt curve analysis, which consisted of incrementally increasing reaction temperature $\left(0.5^{\circ} \mathrm{C} / 10 \mathrm{~s}\right)$ from 55 to $95^{\circ} \mathrm{C}$. The negative first derivative of the melt curve (fluorescence vs temperature) plotted against temperature will yield a single peak ( $T_{\mathrm{m}}$ of product) if primers are specific to the gene of interest.

Real-time detection and quantitation of PCR product. Formation of PCR product was monitored in real time using the MyiQ Single-Color Real-Time PCR Detection System (Bio-Rad). Fluorescence of SYBR Green I was captured at $72^{\circ} \mathrm{C}$. Threshold for detection of PCR product above background was set at $10 \times$ the SD of mean background fluorescence for all reactions. Background fluorescence was determined from cycles 1-5 before exponential amplification of product and subtracted from raw fluorescence of each reaction/cycle. Threshold for detection of PCR product fell within the log-linear phase of amplification for each reaction. Threshold cycle $\left(C_{\mathrm{T}}\right.$; number of cycles to reach threshold of detection) was determined for each reaction.

Relative quantitation of gene expression. Relative gene expression was determined using the $2^{-\Delta \Delta C t}$ method (Livak and Schmittgen, 2001). Mean $C_{\mathrm{T}}$ of triplicate measures was computed for each sample. Sample mean $C_{\mathrm{T}}$ of GAPDH or 18 s ribosomal RNA (internal control genes) was subtracted from the sample mean $C_{\mathrm{T}}$ of the respective gene of interest $\left(\Delta C_{\mathrm{T}}\right)$. The sample with the absolute highest mean $\Delta C_{\mathrm{T}}$ was selected as a calibrator and subtracted from the mean $\Delta C_{\mathrm{T}}$ of each experimental sample $\left(\Delta \Delta C_{\mathrm{T}}\right) \cdot 2^{-\Delta \Delta \mathrm{Ct}}$ yields fold change in gene expression of the gene of interest normalized to the internal control gene expression and relative to the calibrator sample.

Data analysis. All statistical analyses were conducted using StatView statistical program. Unless otherwise noted, a one-way ANOVA was conducted and followed by Fisher's post hoc tests when appropriate. RT-PCR data are plotted as "relative expression," which refers to expression of the gene of interest ( $A r c$ or c-fos) relative to expression of the housekeeping gene $(G A P D H)$. In all experiments, gene expression of experimental subjects was compared with home cage control (basal) expression. Outliers from each triplicate RT-PCR were excluded from the analysis. The criterium for outlier detection was set at 2 SD beyond the mean of RTPCR triplicate measures. Arc and c-fos were quantified in separate reactions and therefore encountered error unique to each run. Therefore, $n$ values may differ in the final analysis.

\section{Results}

\section{Contextual fear conditioning induces Arc mRNA in the hippocampus}

The purpose of the first experiment was to establish that contextual fear conditioning induces Arc mRNA in the hippocampus. Rats were killed immediately $(n=4), 15 \mathrm{~min}(n=4)$, or $30 \mathrm{~min}$ $(n=4)$ after contextual fear conditioning, and Arc mRNA was compared with that expressed in home cage control rats $(n=6)$. IEG expression in whole hippocampus was measured with quantitative real-time RT-PCR. As shown in Figure 1, there were significant differences among the groups $\left(F_{(3,14)}=4.56 ; p<0.01\right)$. Post hoc tests indicate that both the 15 and 30 min conditions differed from the home cage condition $(p<0.05$ and 0.01 , respectively). In addition, the $30 \mathrm{~min}$ condition differed from the immediate condition $(p<0.01)$. It is clear from this experiment that our contextual fear conditioning procedure induced Arc mRNA expression in the hippocampus. This is consistent with the report by Lee et al. (2004) in that Arc protein is elevated in

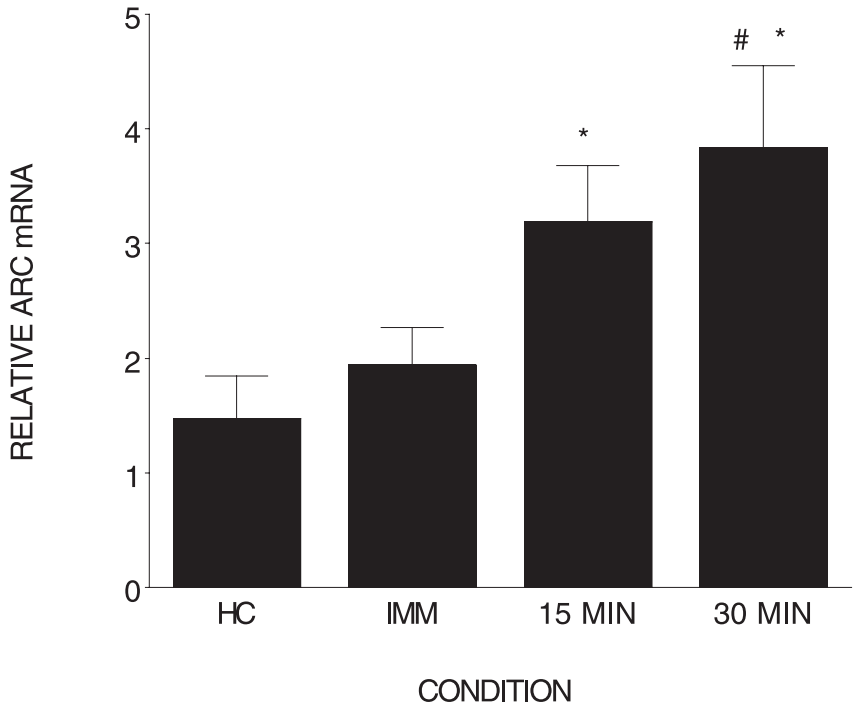

Figure 1. Contextual fear conditioning elevates Arc mRNA in the hippocampus. Relative Arc $\mathrm{mRNA}$ ( \pm SEM) measured in the hippocampus immediately or 15 or 30 min after contextual fear conditioning is shown. * Differs from home cage (HC); \#, differs from immediate (IMM). Error bars represent SEM.

CA1 region of hippocampus 2, 4, and $6 \mathrm{~h}$ after contextual fear conditioning.

\section{Arc and c-fos mRNA are increased in the hippocampus after context exposure or context plus shock but not after immediate shock}

Several theorists (Fanselow and Rudy, 1998; Fanselow, 2000; Rudy et al., 2004) have argued that contextual fear conditioning involves two learning processes: (1) the rat must acquire a unitary or conjunctive representation of the context, and (2) the context representation must be associated with shock. In these theories, the hippocampus is assumed to be responsible for acquiring the representation of the context. This view suggests that different components of the rat's experience during contextual fear conditioning might contribute differentially to the activation of the IEGs that were observed in the first experiment.

Thus, in experiment 2, we determined the effect of three components of the experience on the expression of Arc and c-fos in the hippocampus: (1) context exploration $(n=4)$, (2) immediate shock $(n=6)$, and (3) context plus shock (contextual fear conditioning; $n=4)$. Arc expression was measured in rats killed 30 min after training, and c-fos expression was obtained from rats killed $60 \mathrm{~min}$ after conditioning. These conditions were compared against rats killed from their home cage $(n=5)$. Rats in the context-only condition were allowed to explore the context for 5 min. Rats in the immediate shock group were taken from their home cage, placed into the conditioning chamber, and immediately shocked. Rats in the context plus shock condition were place in the context for $5 \mathrm{~min}$ and then received a single $2 \mathrm{~s}$ shock.

\section{Arc expression}

Figure 2 shows that there were differences in $A r c$ mRNA among the four conditions $\left(F_{(3,15)}=3.57 ; p<0.05\right) 30$ min after training. Post hoc analysis revealed that subjects in both the context and context plus shock condition displayed elevated Arc expression in hippocampus compared with the home cage control condition $(p<0.05$ and 0.01$)$. Immediate shock did not significantly elevate Arc expression $(p=0.24)$. 


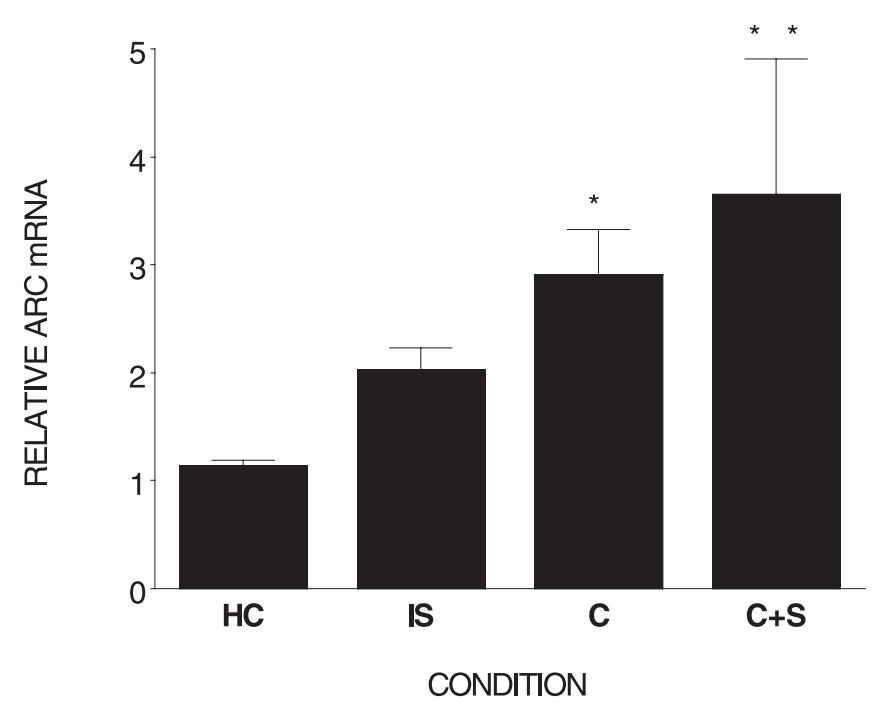

Figure 2. The components of contextual fear conditioning differentially elevate Arc mRNA in hippocampus. Relative $\operatorname{Arc~mRNA~(~} \pm$ SEM) measured in the hippocampus is shown. Rats were killed 30 min after an immediate shock (IS), context exploration (C), context plus shock (C+S), or removal from the home cage $(\mathrm{HC}) .{ }^{*}$, Differs from home cage and immediate shock; ${ }^{*}$, differs from home cage. Error bars represent SEM.

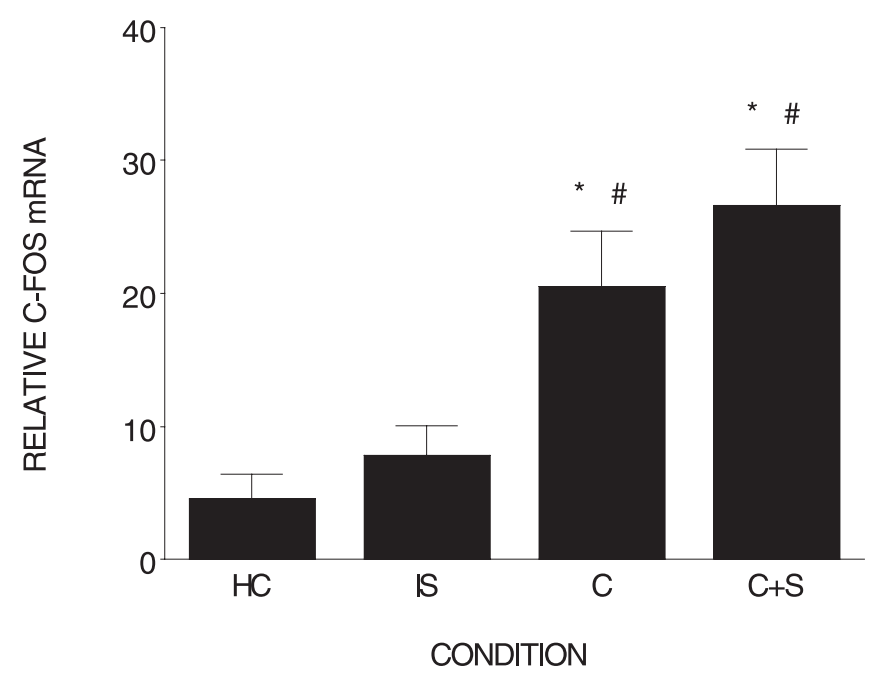

Figure 3. The components of contextual fear conditioning differentially elevate c-fos mRNA in the hippocampus. Relative c-fos mRNA ( \pm SEM) measured in the hippocampus is shown. Rats were killed 60 min after an immediate shock (IS), context exploration (C), context plus shock $(C+S)$, or removal from the home cage $(\mathrm{HC}) .{ }^{*}$, \#, Differs from home cage and immediate shock. Error bars represent SEM.

$c$-fos expression

Figure 3 shows that there were differences in c-fos expression among the four conditions $\left(F_{(3,18)}=9.77 ; p<0.001\right) 60$ min after training. Post hoc analysis revealed that rats in both the context and context plus shock conditions displayed elevated c-fos mRNA compared with the home cage control condition $(p<$ 0.005 and $p<0.001)$. Both the context $(n=5)$ and context plus shock $(n=6)$ conditions also differed from the immediate shock condition $(n=6)(p<0.02$ and $p<0.001)$. However, the difference between the immediate shock $(n=4)$ and home cage control condition $(n=6)$ was not significant $(p=0.502)$. In the previous experiments, there was no significant increase in $A r c$ or c-fos in the hippocampus 30 or 60 min, respectively, after immediate shock. This suggests that, as reflected by c-fos and Arc ex-

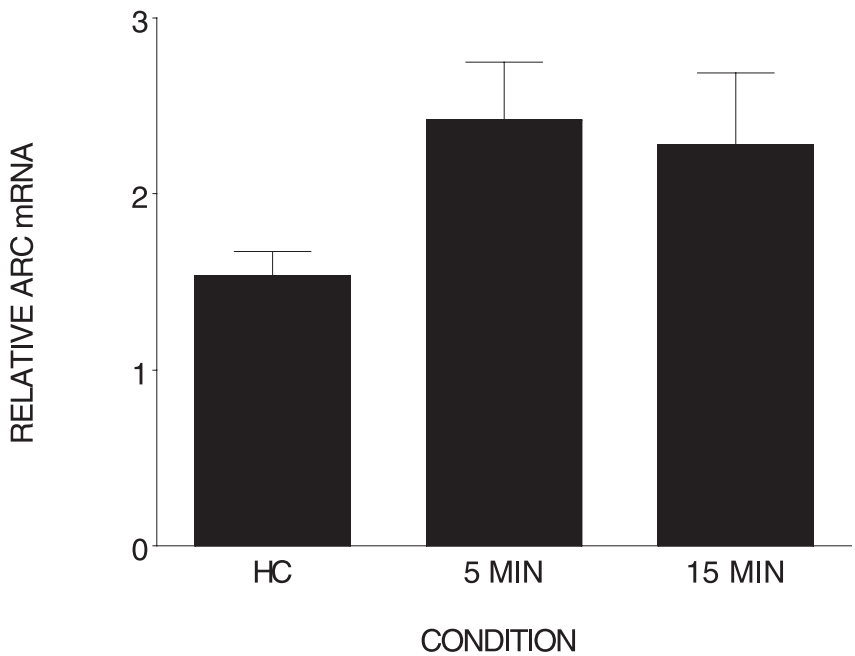

Figure 4. Immediate shock does not significantly elevate Arc mRNA in the hippocampus. Relative Arc mRNA ( \pm SEM) was measured in the hippocampus 5 or 15 min after an immediate shock and removal from the home cage (HC). There were no significant differences among the groups. Error bars represent SEM.

pression, the hippocampus does not directly process immediate shock.

However, it is possible that a footshock induces IEG expression in the brain within minutes after the experience (Rosen et al., 1998), and we missed this early induction in the previous studies. There is, in fact, evidence that $A r c$ is present in the cell nucleus within minutes of a behavioral experience or neural stimulation (Guzowski et al., 1999; Vazdarjanova and Guzowski, 2004). Thus, it is possible that Arc may be detected at an earlier time point. Therefore, we asked whether immediate shock increased Arc mRNA compared with the home cage control condition $(n=$ $5)$ in rats killed $5 \min (n=6)$ or $15 \min (n=5)$ after the shock. As shown in Figure 4, although there was a small increase in Arc expression at both time points, there were no differences among the conditions $\left(F_{(2,13)}=2.255 ; p=0.144\right)$. We found no evidence that immediate shock produces elevated Arc expression in the hippocampus 5 or $15 \mathrm{~min}$ after the experience.

In summary, the first two experiments establish that both exposure to the context and context plus shock (contextual fear conditioning) increase IEG expression in the hippocampus. The effect of shock itself is somewhat unclear. Although shock had no effect on c-fos expression, in two experiments, it did result in a small but not significant increase in Arc expression. Perhaps with larger $n$ values, this small difference would be significant. Nevertheless, at best, shock had a small impact on IEG expression in hippocampus.

\section{Amygdala inactivation reduces Arc mRNA and c-fos in the} hippocampus associated with contextual fear conditioning It is clear from the previous experiments that contextual fear conditioning induces $A r c$ and c-fos mRNA in the hippocampus. The purpose of experiment 3 was to determine whether the BLA modulates Arc and c-fos mRNA levels in the hippocampus induced by contextual fear conditioning. To do this, we inactivated the BLA by infusing muscimol into this region before contextual fear conditioning. Muscimol is a $\mathrm{GABA}_{\mathrm{A}}$ receptor agonist that potentiates inhibitory synaptic transmission (Martin, 1991). Huff and Rudy (2004) have reported that this treatment dramatically reduces memory for context that is dependent on the hippocampus. Rats were killed 30 or $60 \mathrm{~min}$ after conditioning and, 


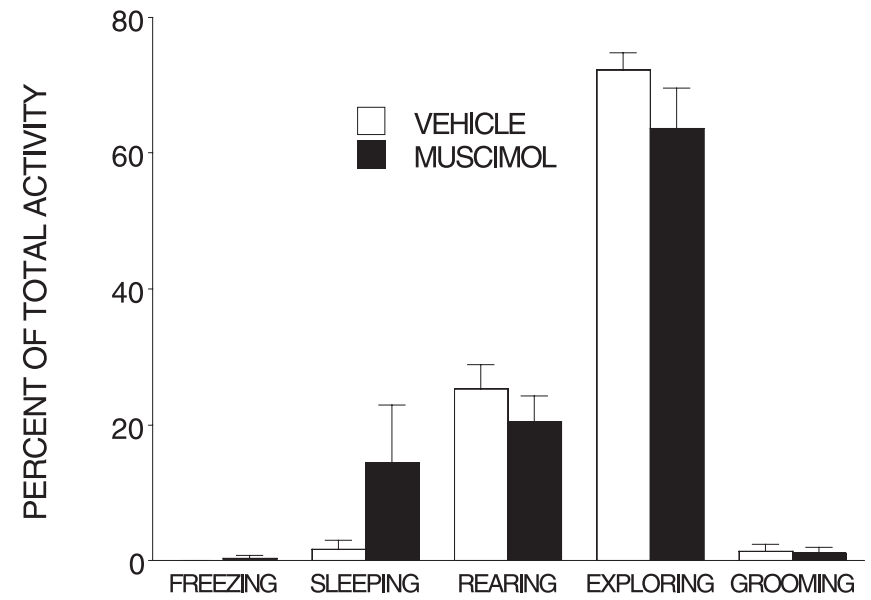

BEHAVIORAL CATEGORY

Figure 5. Muscimol injected into the BLA does not alter behavior before the shock. Mean ( \pm SEM) percentage activity during 5 min of exploration preceding the shock is shown. Muscimol did not influence any behavioral category. Error bars represent SEM.

compared with rats, removed from their home cage and killed. Arc expression was measured in rats killed at both the 30 and 60 min time points, but c-fos expression was only obtained from rats killed 60 min after conditioning. To ensure that inactivation of the BLA before conditioning did not alter the rats' interaction with the context during conditioning, we recorded several categories of behavior that rats normally display in the context before shock presentation.

\section{Behavior}

There were no significant differences in the preshock behavior of rats infused with muscimol $(n=9)$ and those infused with the vehicle $(n=10)$, and the rats spent most of their time before shock exploring the context (Fig. 5).

\section{Arc expression}

There were significant differences among the conditions in $A r c$ expression (Fig. 6) $\left(F_{(4,20)}=6.44 ; p<0.002\right)$. Post hoc tests indicated that both the $30 \mathrm{~min}(n=5)$ and $60 \mathrm{~min}(n=5)$ vehicletreated conditions displayed increased $A r c m R N A$ compared with the home cage $(n=7)$ condition $(p<0.002)$, the muscimoltreated conditions ( $n=4$ and $n=5$ ) did not differ from the home cage control condition but did differ from their respective vehicle-treated counterparts $(p<0.05)$.

\section{c-fos expression}

Figure 7 shows that there were significant differences in c-fos mRNA in the hippocampus between the conditions $\left(F_{(2,10)}=\right.$ 5.95; $p<0.02)$. Post hoc analysis revealed that $c$-fos was elevated in the vehicle-treated condition $(n=4)$ compared with both the home cage $(n=6)$ and muscimol-treated $(n=3)$ condition $(p<$ 0.02 ), and the muscimol-treated condition did not differ from the home cage condition. The results of these experiments clearly demonstrate that muscimol injected into the BLA prevented the induction of hippocampal Arc and c-fos expression by contextual fear conditioning

\section{The effect of amygdala inactivation on Arc mRNA in the} hippocampus associated with context exposure

The observation that context exploration induces Arc expression in the hippocampus is consistent with the report by Guzowski et

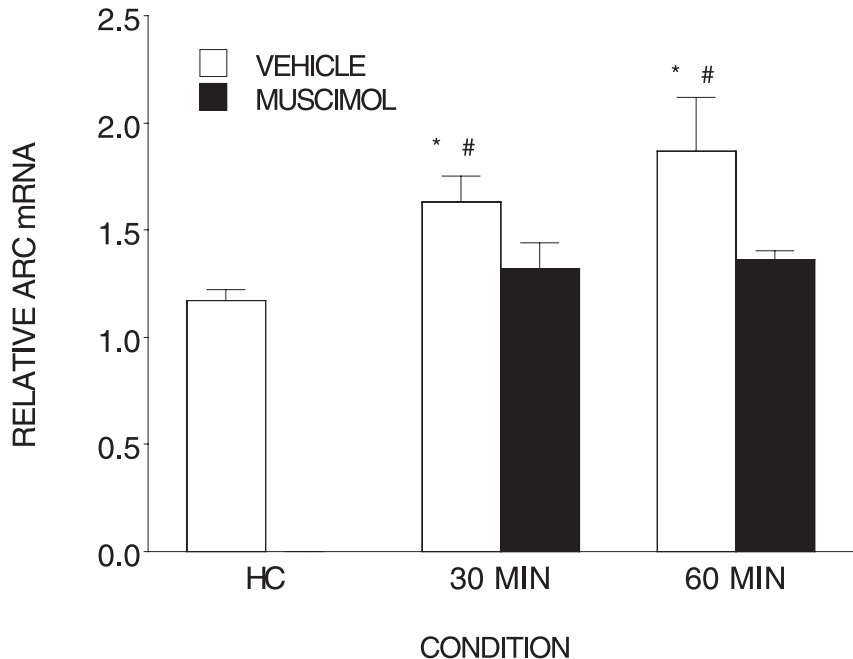

Figure 6. Muscimol injected into the BLA prevents the elevation of Arc mRNA normally produced by contextual fear conditioning. Relative Arc mRNA ( \pm SEM) was measured in the hippocampus after contextual fear conditioning. Either muscimol or vehicle was injected into the $B L A$ region before conditioning. Rats were killed either after removal from the home cage $(\mathrm{HC})$ or 30 or 60 min after conditioning. ${ }^{*}$, Differs from home cage; \#, differs from respective muscimol condition. Error bars represent SEM.

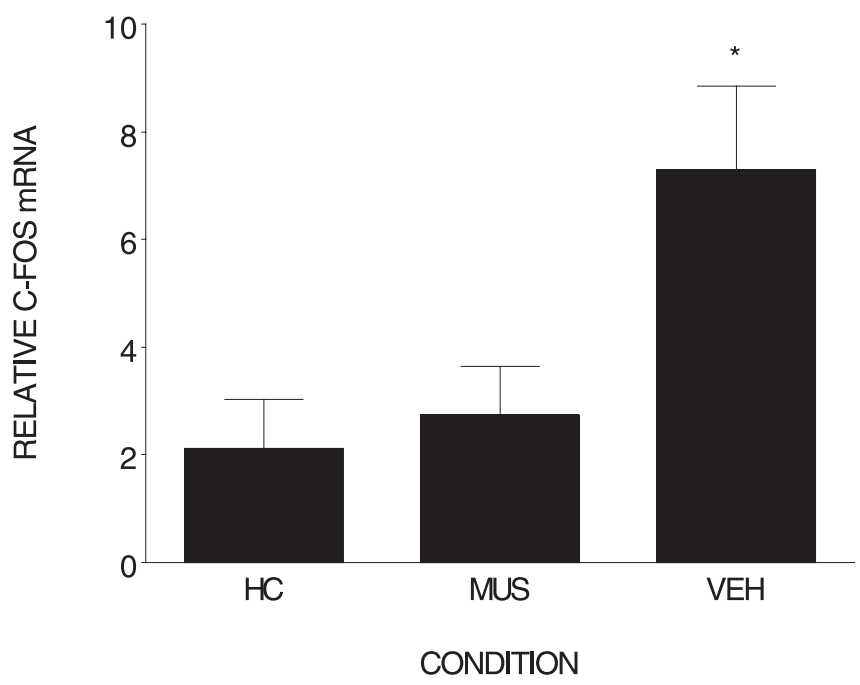

Figure 7. Muscimol injected into the BLA prevents the elevation of c-fos mRNA normally produced by contextual fear conditioning. Relative c-fos mRNA ( \pm SEM) was measured in the hippocampus after contextual fear conditioning. Either muscimol (MUS) or vehicle (VEH) was injected into the BLA region before conditioning. Rats were killed either after removal from the home cage $(\mathrm{HC})$ or 60 min after conditioning. ${ }^{*}$, Differs from home cage and vehicle. Error bars represent SEM.

al. (1999) that context exploration induces Arc in the hippocampus and, with our observations, that damage to the hippocampus impairs learning about context (Rudy et al., 2002). We also reported that muscimol injected into the amygdala impairs the rats' memory for context (Huff and Rudy, 2004; Huff et al., 2005). Thus, in experiment 4, we determined whether muscimol injected into the BLA region would reduce the Arc expression associated with context exploration. One might expect that inactivating the amygdala would alter Arc expression produced by the relatively neutral experience of exploring a novel context. However, it is possible that only under more aversive conditions, such as context exploration plus shock experience, will the amygdala modulate Arc expression in hippocampus. Thus, a finding that 


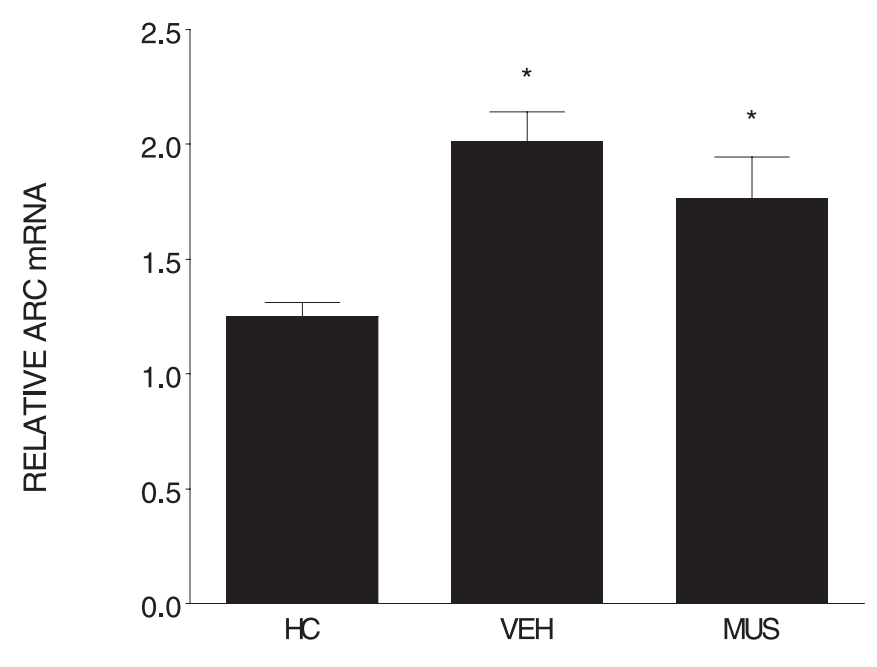

CONDITION

Figure 8. Muscimol injected into the BLA did not influence the elevation of Arc mRNA normally produced by context exposure. Relative Arc mRNA ( \pm SEM) was measured in the hippocampus after exposure to the contextual. Either muscimol (MUS) or vehicle (VEH) was injected into the BLA region before conditioning. Rats were killed either after removal from the home cage (HC) or 30 min after conditioning. * Differs from home cage. Error bars represent SEM.

inactivating the amygdala before context exploration does not alter Arc expression would be consistent with McGaugh's (2004) view that the amygdala is involved in the consolidation of emotionally arousing memories.

Three conditions were compared: (1) home cage control ( $n=$ $7)$ rats were removed from their home cage and killed immediately; (2) context exploration $(n=6)$ rats were injected with vehicle and returned to their home cage, and 60 min later they were transported to the context where they remained for $5 \mathrm{~min}$; and (3) muscimol plus context exploration $(n=7)$ rats were infused with muscimol $60 \mathrm{~min}$ before being transported to the context. Rats in the last two conditions were killed $30 \mathrm{~min}$ after being returned to their home cage. We chose this time point, because data from experiment 2 demonstrate that $A r c$ mRNA is increased in the hippocampus $30 \mathrm{~min}$ after context exposure.

Figure 8 shows that context exploration markedly increased Arc expression in the hippocampus compared with home cage levels. Injecting muscimol into the BLA before exploration produced a small but nonsignificant reduction in Arc mRNA expression in the hippocampus. An ANOVA revealed differences among the groups $\left(F_{(2,17)}=7.9 ; p<0.004\right)$. Post hoc comparisons indicate that only the home cage condition differed significantly from both muscimol and vehicle conditions $(p<0.001$ and 0.01). There was no significant difference in Arc expression between muscimol and vehicle-treated rats $(p=0.20)$. These data are consistent with McGaugh's (2004) general view that the amygdala is primarily involved in the consolidation of emotionally arousing memories.

\section{Discussion}

We previously reported that the BLA modulated memory storage of both memory for an explored context (Huff and Rudy, 2004) and memory for contextual fear conditioning (Passani et al., 2001; LaLumiere et al., 2003; Huff et al., 2005). One way in which the BLA might exert its modulating influence on these memories is by regulating expression of IEGs that contribute to the strengthening of synapses in the hippocampus. Our findings pro- vide support for this hypothesis, because we found that Arc and c-fos mRNA are induced in the hippocampus after a context exposure, or context plus shock experience, and BLA inactivation with muscimol attenuated the increase in $A r c$ and c-fos mRNA in the hippocampus associated with a context plus shock experience (contextual fear conditioning). However, we found no evidence that inactivating BLA influenced Arc expression associated with context exploration.

It is important to compare our results with those reported recently by McIntyre et al. (2005). They reported that a posttraining infusion of clenbuterol ( $\beta$-adrenergic agonist) into the BLA increased Arc protein in the hippocampus, but that an infusion of lidocaine decreased Arc protein associated with inhibitory avoidance learning. However, they found no evidence that the amygdala regulates the expression of Arc or c-fos mRNA, although they expected to see such an influence. Thus, our findings that inactivating the amygdala reduced Arc mRNA expression associated with contextual fear conditioning are inconsistent, but not incompatible, with their results. Not only did we find that inactivating the amygdala reduced Arc mRNA, it also reduced the expression of c-fos $m R N A$. It is difficult to know the source of this discrepancy, because our experiments differ in many ways, including: (1) the type of conditioning, contextual fear conditioning versus inhibitory avoidance conditioning; (2) drugs used to influence the amygdala, muscimol versus lidocaine; (3) timing of injection in relation to the training (before vs after); (4) shock intensity, $1.5 \mathrm{~mA}, 2 \mathrm{~s}$ versus $0.48 \mathrm{~mA}, 1 \mathrm{~s}$; and (5) techniques for measuring the expression of the genes, real-time PCR versus in situ hybridization.

That there are some inconsistencies between our results and those of McIntyre et al. (2005) should not obscure the fact that both sets of data support the important hypothesis that the amygdala modulates both hippocampal-dependent memories and gene products associated with the behavioral experience that produces the memory. Thus, one might conclude that amygdaladependent processes can regulate both the induction of Arc mRNA and Arc protein.

It is not clear why inactivating the amygdala before contextual fear conditioning blocked the induction of IEGs in the hippocampus but did not significantly influence $\operatorname{Arc} m R N A$ expression induced by context exposure. Given that the context plus shock experience is more aversive/stressful than just context exposure, this result could be viewed as consistent with McGaugh's (2004) general view that the amygdala is primarily involved in the consolidation of emotionally arousing memories.

We previously reported that inactivating the amygdala with muscimol significantly impaired the rat's learning about the context (Huff and Rudy, 2004). We noted in the introduction that it is possible that the modulating influence of the amygdala on the context memory may be via its effect on the expression of Arc mRNA. Unfortunately, this hypothesis draws no support from the data presented here, because inactivating the amygdala did not prevent context exploration from elevating Arc expression. However, given the finding by McIntyre et al. (2005) that inactivating the amygdala decreased Arc protein associated with inhibitory avoidance learning without reducing the level of Arc mRNA, it is still possible that the amygdala could modulate the consolidation of the context memory via its influence on the translation of $A r c$ mRNA or be influencing expression of another IEG that we did not measure.

We decomposed the elements of the contextual fear conditioning experiment, context exploration plus shock, into its components: context exploration and immediate shock. This com- 
parison revealed that context exploration and context plus shock increased IEG expression in the hippocampus. Immediate shock had no effect on c-fos expression and a small, but not significant, effect on Arc expression in the hippocampus. That shock alone has little impact on Arc and c-fos expression is consistent with the report by Hall et al. (2000) that contextual fear conditioning, but not shock alone, elevates BDNF mRNA expression in the hippocampus. Together, these results suggest that IEG expression in the hippocampus is relatively insensitive to shock itself. Moreover, Guzowski et al. (1999) reported that the activation patterns of Arc expression produced by context exploration are quite specific to the particular context that is explored by the animal. These facts coupled with our finding that IEG expression after context exposure did not differ from that produced by context plus shock suggest that the context exposure itself is the primary driver of IEG expression in the hippocampus. This conclusion is consistent with several theories that assume that the hippocampus contributes to contextual fear conditioning primarily by constructing a representation of the context in which shock occurs (Rudy and O'Reilly, 1999; Fanselow, 2000; Maren, 2001; Rudy et al., 2004).

It is interesting to note that Hess et al. (1997) measured c-fos mRNA levels in both the amygdala and hippocampus after the rat's exploration of a novel odor conditioning chamber. They found especially high c-fos levels in both the basolateral region of the amygdala and hippocampus in rats killed immediately after 30 min of exploration. Our data suggest that the high level of c-fos in the hippocampus was dependent on activity in BLA neurons (as represented by the high level of c-fos) and not vice versa.

There are several ways that $A r c$ and c-fos could contribute to memory storage in the hippocampus. Arc is an effector IEG that has direct effects on the neuron. Arc mRNA and protein are found at recently activated synapses, and studies reveal that Arc protein interacts with the cytoskeletal protein actin (Lyford et al., 1995; Steward et al., 1998; Wallace et al., 1998). This suggests that Arc may be involved in the alteration of dendritic scaffolding to support synaptic plasticity after learning. In contrast, c-fos is a transcription factor IEG that regulates induction of other genes and may have less direct effects on synaptic plasticity (for review, see Hughes and Dragunow, 1995). Future experiments are needed to address how these two IEGs work in concert to support long-term memory formation in the hippocampus and their functional significance at the cellular level in contextual fear conditioning.

In conclusion, our experiments indicate that IEG activation in the hippocampus is primarily driven by the context exploration component of a contextual fear conditioning experience, and that the BLA plays an important role in regulating gene expression induced in the hippocampus by contextual fear conditioning. Thus, these data join those reported by McIntyre et al. (2005) to support the hypothesis that the amygdala modulates memory storage in the hippocampus by contributing to the regulation of gene products, such as $A r c$, that might participate in modifying synaptic strength.

\section{References}

Altschul S, Madden T, Schaffer A, Zhang J, Zhang Z, Miller W, Lipman DJ (1997) Gapped BLAST and PSI-BLAST: a new generation of protein database search programs. Nucleic Acids Res 25:3389-3402.

Barrientos RM, O'Reilly RC, Rudy JW (2002) Memory for context is impaired by injecting anisomycin into dorsal hippocampus following context exploration. Behav Brain Res 134:291-298.

Campeau S, Falls W, Cullinan W, Helmreich D, Davis M, Watson SJ (1997) Elicitation and reduction of fear: behavioural and neuroendocrine indices and brain induction of the immediate-early gene c-fos. Neuroscience 78:1087-1104.

Chomczynski P, Sacchi N (1987) Single-step method of RNA isolation by acid guanidinium thiocyanate-phenol-chloroform extraction. Anal Biochem 162:156-159.

Fanselow MS (2000) Contextual fear, gestalt memories, and the hippocampus. Behav Brain Res 110:73-81.

Fanselow MS, Rudy JW (1998) Convergence of experimental and developmental approaches to animal learning and memory processes. In: Mechanistic relationships between development and learning: beyond metaphor (Carew T, Menzel R, Shatz C, eds), pp 15-29. Chichester, UK: Wiley.

Gold P, van Burskirk R (1976) Effects of posttrial hormone injections on memory processes. Horm Behav 7:509-517.

Grimm R, Schicknick H, Riede I, Gundelfinger ED, Herdegen T, Zuschratter W, Tischmeyer W (1997) Suppression of c-fos induction in rat brain impairs retention of a brightness discrimination reaction. Learn Mem 3:402-413.

Guzowski JF (2002) Insights into immediate early gene function in hippocampal memory consolidation using antisense oligonucleotide and fluorescent imaging approaches. Hippocampus 12:86-104.

Guzowski JF, McNaughton BL, Barnes CA, Worley PF (1999) Environmentspecific expression of the immediate-early gene Arc in hippocampal neuronal ensembles. Nat Neurosci 2:1120-1124.

Guzowski JF, Setlow B, Wagner EK, McGaugh JL (2001) Experiencedependent gene expression in the rat hippocampus after spatial learning: a comparison of the immediate-early genes Arc, c-fos, and zif268. J Neurosci 21:5089-5098.

Hall J, Thomas K, Everitt B (2000) Rapid and selective induction of BDNF expression in the hippocampus during contextual learning. Nat Neurosci 3:533-535.

Herrera D, Robertson H (1996) Activation of c-fos in the brain. Prog Neurobiol 50:83-107.

Hess U, Gall CM, Granger R, Lynch G (1997) Differential patterns of c-fos mRNA expression in amygdala during successive stages of odor discrimination learning. Learn Mem 4:262-283.

Huff NC, Rudy JW (2004) The amygdala modulates hippocampaldependent context memory formation and stores cue-shock associations. Behav Neurosci 118:53-62.

Huff NC, Wright-Hardesty K, Matus-Amat P, Higgins E, Rudy JW (2005) Context pre-exposure obscures amygdala modulation of contextual fear conditioning. Learn Mem 12:456-460.

Hughes P, Dragunow M (1995) Induction of immediate-early genes and the control of neurotransmitter-regulated gene expression within the nervous system. Pharmacol Rev 47:133-178.

LaLumiere RT, Buen TV, McGaugh JL (2003) Post-training intrabasolateral amygdala infusions of norepinephrine enhance consolidation of memory for contextual fear conditioning. J Neurosci 23:6754-6758.

Lee J, Everitt B, Thomas J (2004) Independent cellular processes for hippocampal memory consolidation and reconsolidation. Science 304:839-843.

Link W, Konietsko U, Kauselmann G, Krug M, Schwanke B, Frey U, Kuhl D (1995) Somatodendritic expression of an immediate early gene is regulated by synaptic activity. Proc Natl Acad Sci USA 92:5734-5738.

Livak K, Schmittgen T (2001) Analysis of relative gene expression data using real-time quantitative PCR and the 2(-Delta Delta C(T)) Method. Methods 25:402-408.

Lyford GL, Yamagata K, Kaufmann WE, Barnes CA, Sanders LK, Copeland NG, Gilbert DJ, Jenkins NA, Lanahan AA, Worley PF (1995) Arc, a growth factor and activity-regulated gene, encodes a novel cytoskeletonassociated protein that is enriched in neuronal dendrites. Neuron 14:433-445.

Maren S (2001) Neurobiology of pavlovian fear conditioning. Annu Rev Neurosci 24:87-931.

Martin JH (1991) Autoradiographic estimation of the extent of reversible inactivation produced by microinjections of lidocaine and muscimol in the rat. Neurosci Lett 127:160-164.

Matus-Amat P, Higgins E, Barrientos R, Rudy JW (2004) The role of the dorsal hippocampus in the acquisition and retrieval of context memory representations. J Neurosci 24:2431-2439.

McGaugh JL (2002) Memory consolidation and the amygdala, a systems perspective. Trends Neurosci 25:456-462. 
McGaugh JL (2004) The amygdala modulates the consolidation of memories of emotionally arousing experiences. Annu Rev Neurosci 27:1-28.

McGaugh JL, Roozendaal B, Cahill L (1999) Modulation of memory storage by stress hormones and the amygdala complex. In: The new cognitive neurosciences, Ed 2 (Gazing M, ed). Cambridge, MA: MIT.

McIntyre CK, Power AE, Roozendaal B, McGaugh JL (2003) Role of the basolateral amygdala in memory consolidation. Ann NY Acad Sci 985:273-293.

McIntyre CK, Miyoshita T, Setlow B, Marjon KD, Steward O, Guzowski JF, McGaugh JL (2005) Memory-influencing intra-basolateral amygdala drug infusions modulate expression of Arc protein in the hippocampus. Proc Natl Acad Sci USA 102:10718-10723.

Montag-Sallaz M, Buonviso N (2002) Altered odor-induced expression of c-fos and arg 3.1 immediate early genes in the olfactory system after familiarization with an odor. J Neurobiol 52:61-72.

Packard M, Williams C, Cahill L, McGaugh JL (1995) The anatomy of a memory modulatory system: from periphery to brain. In: Neurobehavioral plasticity (Spear N, Spear L, Woodruff M, eds), pp 149-185. Hillsdale, NJ: Erbium.

Passani MB, Cangioli I, Baldi E, Bucherelli C, Mannaioni PF, Blandina P (2001) Histamine H3 receptor-mediated impairment of contextual fear conditioning and in-vivo inhibition of cholinergic transmission in the rat basolateral amygdala. Eur J Neurosci 14:1522-1532.

Paxinos G, Watson C (1998) The rat brain in stereotaxic coordinates, Ed 4. San Diego: Academic.

Roozendaal B (2003) Systems mediating acute glucocorticoid effects on memory consolidation and retrieval. Prog Neuropsychopharmacol Biol Psychiatry 27:1213-1223.

Rosen JB, Fanselow M, Young S, Sitcoske M, Maren S (1998) Immediateearly gene expression in the amygdala following footshock stress and contextual fear conditioning. Brain Res 796:132-142.

Rudy JW, O’Reilly RC (1999) Contextual fear conditioning, conjunctive representations, pattern completion, and the hippocampus. Behav Neurosci 113:867-880.

Rudy JW, Barrientos R, O'Reilly RC (2002) The hippocampal formation supports conditioning to memory of a context. Behav Neurosci 116:530-538.

Rudy JW, Huff NC, Matus-Amat P (2004) Understanding contextual fear conditioning: insights from a two-process model. Neurosci Biobehav Rev 28:675-685.

Steward O, Wallace CS, Lyford GL, Worley PF (1998) Synaptic activation causes the mRNA for the IEG Arc to localize selectively near activated postsynaptic sites on dendrites. Neuron 21:741-751.

Tischmeyer W, Grimm R (1999) Activation of immediate early genes and memory formation. Cell Mol Life Sci 55:564-574.

Vazdarjanova A, Guzowski JF (2004) Differences in hippocampal neuronal population responses to modifications of an environmental context: evidence for distinct, yet complementary, functions of CA3 and CA1 ensembles. J Neurosci 24:6489-6496.

Wallace CS, Lyford GL, Worley PF, Steward O (1998) Differential intracellular sorting of immediate early gene mRNAs depends on signals in the mRNA sequence. J Neurosci 18:26-35. 